\title{
A Study on the Systemic Disaster Safety Management in Response to Complex Risk Society: Case of Korea
}

\author{
Ji-Yeon YOO \\ Department of Information and Security Management \\ Sangmyung University, Republic of Korea
}

\begin{abstract}
Recent disasters are becoming increasingly diversified, larger and increasingly uncertain. However, disaster management still lacks various research and lessons, and it exposes various problems in management. Disruption of the command system, a number of non-practical response manuals, failure to function effectively at the local government headquarters, a lack of unified system, failure of national emergency support function, disruption of central control tower. The majority of responding problems are due to the manual method of approaching each type of disaster and the distributed management system.In this study, we aim to review the disaster safety management plan from the viewpoint of total value chain aiming at total optimization. To this end, the system should be directed to a systematic model that is characterized by a systematic approach to disaster management and safety management.
\end{abstract}

Keywords : Complex Risk Society, Disaster Safety Management, Systemic Approach

\section{INTRODUCTION}

Disaster safety issues have focused on understanding organizational errors to reduce disasters, emphasizing performance failures. It focuses on management functions, guidelines, domestic and international standards and quality principles in order to build an organization's safety management system. However, this approach may be a step-by-step approach to safety management and is not suitable for effectively managing risk. This is because safety management activities do not mean prevention and preparation activities as a disaster response. In this context, it is necessary to link the safety management process with the disaster management process, and to manage it in a comprehensive manner, including policy, organization, planning, auditing and performance measurement functions. Moreover, the time to respond to disasters can be extremely short and the need for prevention as an everyday response is becoming important. It is necessary to consider and apply a systemic approach as a way to effectively address strategic, operational and organizational issues related to disaster safety management.

II.

DISASTER SAFETY MANAGEMENT CONSIDERED SYSTEMIC APPROACH (SDSMM)

A system is a set of interrelated components that refers to the process by which components interact organically toward a goal. Feedback is given to the whole system to determine whether the goal has been reached. In other words, it is an orderly combination of parts in which independently and mutually related elements form a rational whole through joint effort under the same purpose and form a functional and organizational form in order to achieve a predetermined goal[1].

Figure 1. Systematic approach vs. Systemic approach
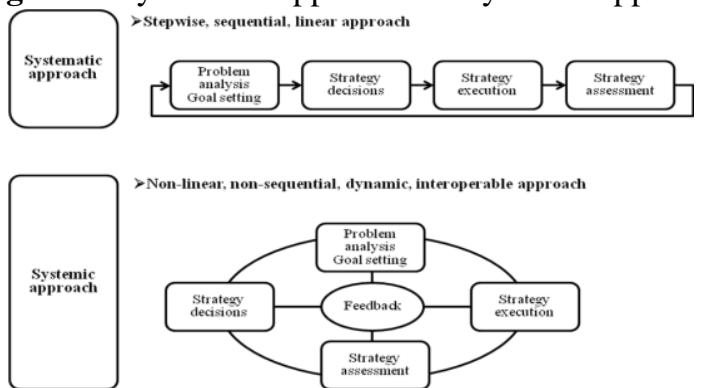

※ Source: Fahmy and Lagowski (2011)[1] Reconstruction 
If the systematic approach is aimed at achievement-oriented objectivity as a step wise, linear process, the systemic approach is a process-oriented construct that is a cyclical process in which contexts are considered $^{1}$.In other words, the systematic approach is a general and ambiguous frame of thinking, in which the problem or situation is viewed as a whole, with its consequences, internal interactions, external connections, and integrated perception of contextual location[2].

Table 1: Systematic approach vs. Systemic approach

\begin{tabular}{|c|c|c|}
\hline & Systematic approach & Systemic approach \\
\hline Meaning & Order, procedure, interval & Organized total \\
\hline Design Procedure & Stepwise, linear & $\begin{array}{c}\text { Consider contextual variables } \\
\text { simultaneously }\end{array}$ \\
\hline Design Method & By prior written procedures & $\begin{array}{c}\text { Flexign considering situational } \\
\text { characteristics }\end{array}$ \\
\hline
\end{tabular}

※ Source: Alexander (1964)

Disaster safety management is structured to systematically manage safety management, consisting of premarket entry, consumption stage and post-accident stages, prevention, contrast, response and recovery. In order to secure the effectiveness of countermeasures, the demand for prevention and countermeasures is high, but when establishing the actual strategy, the administrative system centered on administrative office works to establish the policy of entering the market or consumption phase.

Figure 2. Systematic approach vs. Systemic approach towards disaster safety management

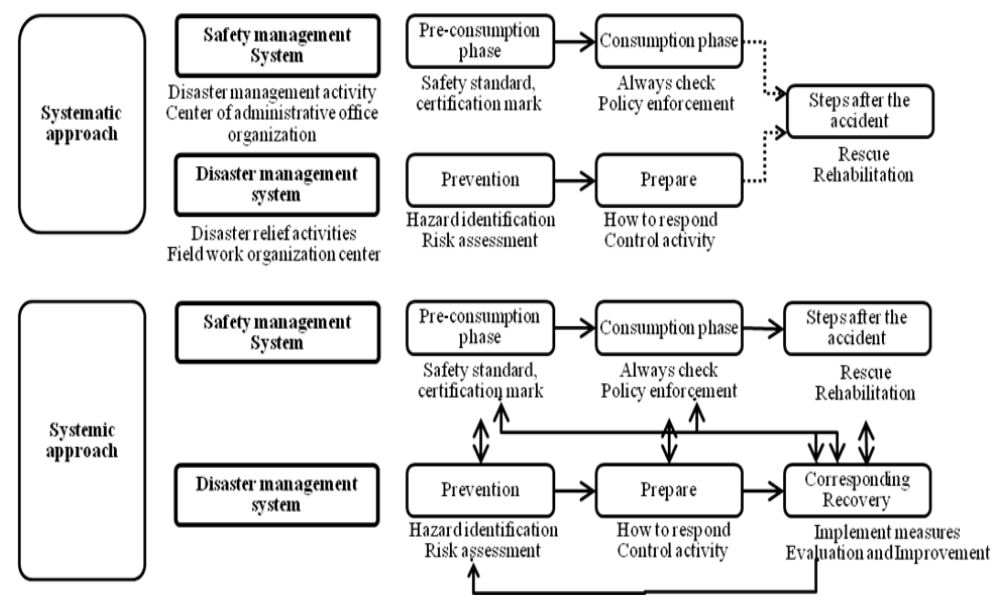

Therefore, an effective construction model for safety management systems and disaster management systems are required as a whole. The SDSMM (Systemic Disaster-Safety Management Model) is a systemic approach that is proposed as a model for this. In the disaster safety management model considered systemic approach, the system of safety management and disaster management is divided into stages and functions and relocated as shown in Figure $3^{2}$. First, it consists of three environments in a big frame. The first environment is a safety management environment consisting of strategies and functions for disaster safety management and a general organization. The second environment is a disaster management environment in which actual safety management policies are implemented and disaster response must be promoted. The third environment is the whole environment as related to disaster safety management. The first environment is close to the system constructed and operated at the central government level whereas the second environment is close to the civilian sector system where actual safety management is implemented and disaster accidents occur. The third environment is an environment in which disaster safety management and disaster incidents are integrated and coordinated.The first environment, the safety management environment, consists of safety-strategy, safetydevelopment, safety-management and safety-co-ordination. The safety strategy (system1) is responsible for establishing strategies that reflect safety values and national beliefs, to deliberate on policies and to make

\footnotetext{
${ }^{I}$ The systematic approach was discussed at the educational engineering level from the mid - 1990s and applied to instructional design. Disaster safety began to be discussed in the early 2000s. It is believed that the discussion and refinement of application in Korea are presented for the first time in this report

${ }^{2}$ The systemic disaster-safety management model (SDSMM) was reconstructed with reference to Santos-Reyes and Beard (2008)[3].

DOI: 10.9790/0837-2203013136 www.iosrjournals.org 32 |Page
}


normative decisions. It also promotes a safety culture at all levels. The goal is to maintain safety at all levels, while the detailed policies are modified and supplemented flexibly according to the safety information (system5) and risk information (system7). Safety R \& D (system2) carries out safety research and development for continuous safety maintenance. It addresses the strengths, weaknesses, opportunities and threats of the overall system and achieves its function according to the safety policy. That is, it maintains the risk within the organization's acceptable range. Attempts to detect and monitor environmental factors to adequately address the various threats and opportunities identified within the overall environment. Safety management (system 3 ) is the directly responsible for managing the risks within the limits and the disaster management environment should ensure that the safety policy is established. It should play a role in predicting and maintaining the advance risks occurring in the disaster management environment. The safety organization (system4) coordinates the activities of stakeholders in the disaster management environment related to the overall disaster safety management environment. It should promote safety strategies and coordinate with other environments (or systems) to meet the needs of the disaster management environment. Safety information (system5) is intended to analyze all information as part of safety R \& D and to develop and plan actions to be taken in response to reported events, to identify causes of concern so similar accidents do not occur in the future. The second environment, the disaster management environment, is where the risk is generated and where the process of the organization proceeds, consisting of safety-function(risk-management) and risk responses. Risk management in the disaster management environment (system6) implements its own safety and risk management policies. It directly handles safety management and risk management, and organizes risk monitoring and processes. It conducts safety planning, resource acquisition and safety monitoring, and performs analysis, forecasting and related activities so as to manage risks in advance. It also shares the risk information (system7) with the safety organization (system4) for monitoring, analysis and forecasting. The response (system8) is responsible for the primary response and promotes response plans and response activities in cooperation with the safety organization (system4). The third environment, the overall environment, operates when the response of the systemic disaster safety management model is required, thereby allowing the disaster management environment to function properly according to the safety management environment and as an external factor when it fails to operate effectively. The local environment continuously monitors the disaster management environment and the future environment interacts with the safety R \& D (system2). In particular, system 9 is installed to audit the safety management environment and the disaster management environment sporadically, to reflect the safety strategy (system 1) in the disaster management environment, and to analyse the safety performance.

Figure 3. Systemic Disaster Safety Management Model (SDSMM)

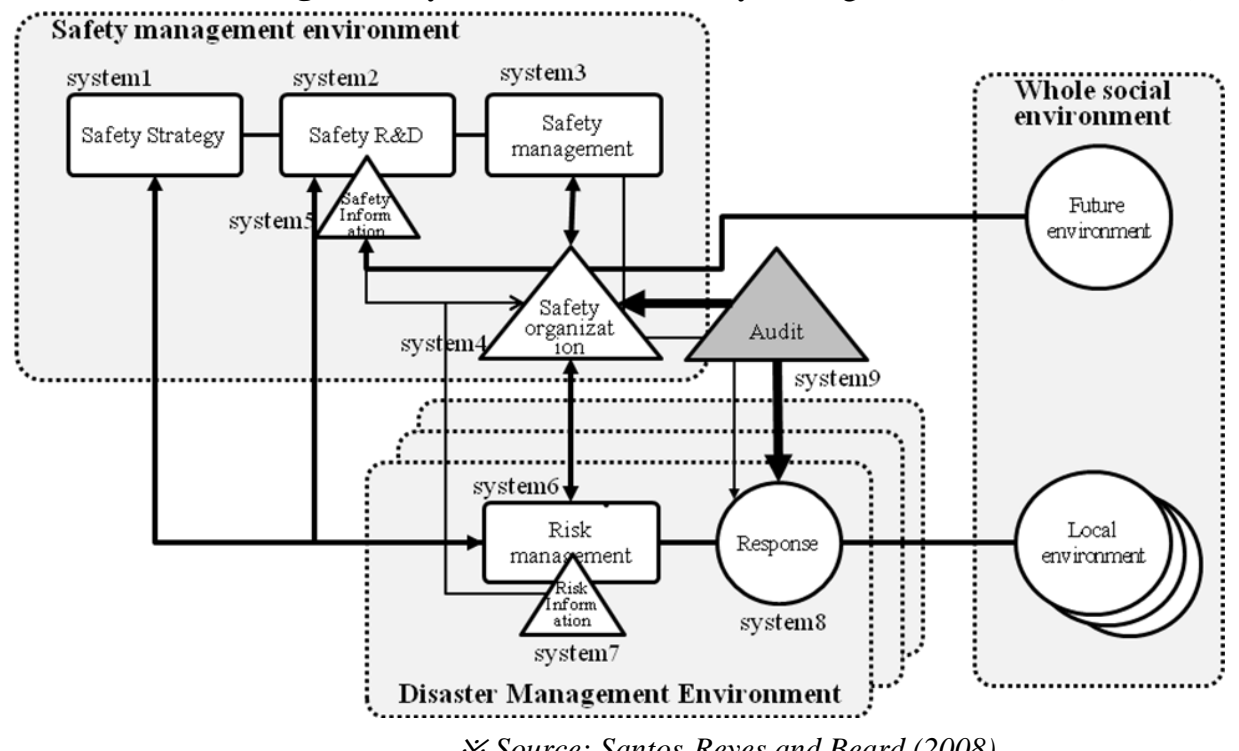

The characteristics of the systemic disaster safety management model are as follows: First, the various structures and systems related to disaster safety are regarded as one environment and the organic relationship is sought. Second, it emphasizes recursive structure and relative autonomy. Repeated structure refers to designing to have a hierarchical structure and interconnectivity for the disaster safety management and the discrete management of individual units in relation to the second environment. Relative autonomy means that, at a certain level, and to have control of safety management operations and disaster response. Thirdly, the function related to disaster safety is composed of a basic unit. 


\section{RESPONSE DEFENSE APPROACH (TDRMA)}

Disaster safety management should address the challenges of existing disaster relief and response approaches, strategies and mechanisms. The disaster management cycle consists of prevention, mitigation, preparedness, response and recovery. Increasing prevention in the prevention and mitigation phase reduces the threat. At present, disaster safety is intertwined with various situations and stakeholders. Knowing this relationship and strengthening the level of contrast will improve the ability to respond. The TDRMA (Total Disaster Risk Management Approach) is required to identify and respond to these various risks. The Total Defense Risk Approach (TDRMA) is to improve the responses by sorting out all common risks and establishing a differentiated response strategy by thoroughly evaluating the risks. In other words, it does not correspond equally to all types of disaster risks, but to different levels of response to disasters by evaluating the likelihood and severity of a disaster[4]. Risk means probability and severity[5]. Likelihood can be classified as extremely rare, rare, unlikely, possible, likely, or certain, depending on the likelihood of occurrence. Secondly, severity can be classified from a mild level to a very severe level, depending on the quantitative and qualitative levels of the casualties that the hazard poses as the risk. It can be classified as major, moderate, minor, and insignificant. The Total Defense Risk Approach (TDRM) is a holistic and aggressive approach to mitigating disasters, focusing on disaster threats and vulnerability analysis and assessment. It resolves disaster management cycle gaps in a way that emphasizes multi-level, multi-dimensional (linkage) approaches and comprehensive coordination and the cooperation of relevant stakeholders. This approach leads to effective integration of interstakeholder action by establishing key strategies for disaster relief and response in a multilevel, multidimensional, comprehensive approach. Three more strategic goals are needed to make the disaster relief issue more fundamental. The first is identifying the root causes of disasters and disaster risk management problems to address various concerns and gaps in the overall stage of the disaster management cycle. The second is the effective prevention, mitigation, preparation and response to disasters to improve the local capacity of disaster risk management. Third, it promotes multilevel, multidimensional and comprehensive coordination and cooperation among stakeholders to integrate community participation and stakeholder action and to ensure optimal use of limited resources. In order to pursue these goals, five implementation strategies are required and implementation strategies are complementary. The five implementation strategies are as follows[6].

First, effective disaster reduction and response through multilevel and multidimensional cooperation are achieved. Because of the complexity and vastness of disaster issues, stakeholders cannot solve problems on their own, so it is essential that a wide range of participants, including national and local levels, nongovernmental organizations and local communities, cooperate. In addition, participants in diverse fields such as environment, economy, industry, education, medical care, construction, agriculture and media should be involved in disaster relief activities to understand the vulnerability of local environment, the risks of disaster and to integrate the actions of stakeholders. To this end, networking mechanisms that link resources, expertise and organizational strengths and capacities are needed, and strategies for disaster relief activities should be established through mutual communication. Second is disaster risk information based decision making through disaster mapping and vulnerability assessment. Vulnerability assessments and disaster mapping for disaster relief and response decisions serve as the primary tool for generating reliable disaster risk information. However, since many communities are not familiar with the use of risk mapping and vulnerability assessment, it is important to recognize ways to assess the risks and vulnerabilities that are commonly used in holistic approaches to disaster relief. In this sense, Hazard Identification \& Risk Analysis (HIRA) is an easy way to identify risks and vulnerabilities and assess them[7].Since risks are potentially harmful to the system, individuals or society due to the complexity of vulnerabilities and threats, risk acceptance should be determined by creating a disaster identification and risk analysis matrix (HIRA risk matrix) according to the magnitude of the risk. This matrix is divided into four units according to the probability of high / low. There is a limit to the analysis of information because it is necessary to identify the damaged characteristics and to analyze the vulnerability in cases where disaster identification rarely occurs. You also need to think about how to use the HIRA matrix because you can look at the Disaster Identification and Risk Analysis (HIRA) matrix differently depending on your point of view.

Figure 4. Disaster Identification and Risk Analysis (HIRA) Risk

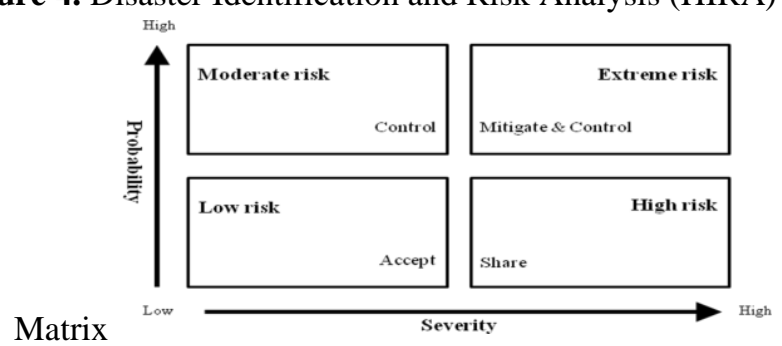

※ Source: The Ontario Public Health Convention (TOPHC) (2014) Reconstruction 
Table 2: Example of disaster impact degree matrix

\begin{tabular}{|c|c|c|c|c|}
\hline Disaster (Rank) & Electric & $\begin{array}{c}\text { Communication (Telephone, } \\
\text { Internet, Mobile phone) }\end{array}$ & $\begin{array}{c}\text { Vaccine } \\
\text { supply chain }\end{array}$ & $\begin{array}{c}\text { Wastewater } \\
\text { management }\end{array}$ \\
\hline Terrorism (1) & $\mathrm{X}$ & $\mathrm{X}$ & $\mathrm{X}$ & $\mathrm{X}$ \\
\hline Hurricanes (1) & $\mathrm{X}$ & $\mathrm{X}$ & $\mathrm{X}$ & $\mathrm{X}$ \\
\hline Fuel shortage (1) & $\mathrm{X}$ & $\mathrm{X}$ & $\mathrm{X}$ \\
\hline Infectious Diseases (1) & & $\mathrm{X}$ & $\mathrm{X}$ & $\mathrm{X}$ \\
\hline Storm (2) & $\mathrm{X}$ & $\mathrm{X}$ & & \\
\hline City fire (3) & & & & $\mathrm{X}$ \\
\hline
\end{tabular}

※ Source: The Ontario Public Health Convention (TOPHC) (2014)

All events cannot be calculated with the calculation of "risk = probability $\times$ severity". Therefore, if the case can neither be controlled nor predicted, it must be ranked first and prepared for. On the other hand, events that can be predicted or that routinely occur should be risk-rated to create a risk ranking and a disaster impact matrix. The Disaster Impact Matrix should be assessed for day-to-day operations and should consider the needs of the emergency / disaster department. Also, when identifying the event impact of an organization, it is necessary to decide how to adjust the risk acceptance based on an understanding of the organization's governance system[8].In addition, risk assessment requires a broad understanding of socio-cultural, economic, environmental, and political dimensions. In addition, it should be discussed strategically with the understanding of the overall context in (1) disaster mapping promotion, vulnerability and risk assessment of the local environmental unit, (2) vulnerability of major facilities and risk assessment collaboration, (3) early warning system improvement and evaluation collaboration.Third, strengthening cooperation through good communication, reliable information exchange, and coordination of stakeholder behavior is required. Information plays an important role in responding effectively to disaster relief. Therefore, proper communication and sharing of critical disaster risk information can improve coordination and integration of behavior among stakeholders in disaster relief and response. To this end, it is necessary to recognize the importance of disaster risk management information systems, public recognition of disaster risk information, and early warning systems to local governments and media. Programs that can be used in this strategy include: (1) improving the level of disaster risk management information systems at various levels, (2) developing competence and skills for media workers and school teachers, (3) integrating information technology and local information, and (4) strengthening early warning systems related to natural disasters .Fourth is ensuring appropriate mechanisms including policies, systems, capacity building, and resources. In order to achieve sustainable development, it is necessary to define systems for the development of disaster relief policies and measures at the national and local environmental levels. In the local environment, it is necessary to respond flexibly to natural disaster risks while maintaining the development policy so as not to increase the vulnerability. Effective disaster mitigation requires activation mechanisms such as policies, systems and systems, capacity enhancement, and resource identification. First, the policy mechanism should be clear and comprehensive in defining the competencies of the local environment - central government - safety organization, and establish the development policy through the strategic consultation planning process in order to resolve any gaps in the disaster management cycle. Second, the actions and contributions of stakeholders must exist in systems including disaster relief and response systems and disaster management systems. Third, continuous and consistent education and training should be accomplished to reduce the disaster effects in the national and local environment and to strengthen the capacity of appropriate response measures. Fourth, budget use and human resource regulations for disaster relief should be correct. This mechanism is more effective when there exists adequate enthusiasm, political will, public service, and sense of responsibility.Fifth, implementation of a disaster risk management process that encompasses both national and local environmental levels is required. The disaster risk management process aims at making the right decisions while using limited resources. This process applies standard principles, processes, and risk management techniques for disaster management and provides a method for systematically managing disaster risks. Management methods consist of six steps: disaster risk setting, disaster risk identification, disaster risk analysis, assessment and disaster risk priority setting, disaster risk handling, monitoring and review. First, in the disaster risk situation setting stage, we establish the strategy, organization, and risk management of the remaining processes. Organizational goals and risk situations for disaster risk issues establish consultative criteria for the assessment and identification of the analytical framework. Second, disaster risk identification identifies the reason for the occurrence of a specific event, the 
resources in the hazardous area, and the risk reduction measures being implemented. Third is the step to analyze the disaster risk in the context of determining the existing control mechanisms. How likely an event will occur should be considered in the analysis and an estimate of the level of risk should be made by analyzing the potential outcome and its scope. The results of this analysis will be used to assess the disaster risk and to set priorities. Next, identify the options for risk in the preventive-response-response-recovery process, select and plan for the fifth step which deals with the disaster risks. At this stage, specific risk management plans and development funding for disaster risks are implemented. In the final step, the implemented process is executed. Sixth, the disaster risk management system performance is also reviewed as a step toward monitoring and reviewing. The advantage of applying risk processes to disaster management standards is that they are formal and systematic decision-making processes and are easy to coordinate, cooperate and integrate by using common terms and systems in all institutions and disciplines.

\section{CONCLUSION}

This study examines the disaster safety management in terms of total optimization and suggests the direction for public system reforms and a related strategy agenda. In the future, a comprehensive review of safety innovation and disaster management strategies, reflecting the policy issues and strategy agenda presented in this study - especially the SDSMM (Systemic Disaster-Safety Management Model), should be promoted. The core of the disaster safety management strategy is how to build an integrated system that takes into account the various functions and specificities of disaster safety management, including strengthening the responsiveness centered on the field and maximizing mutual linkages among them. This is because risk management policies can provide direction and methodology. This will improve the effectiveness and efficiency of disaster safety management and minimize the gaps in policy.

\section{REFERENCES}

[1] Fahmy, A.F.M. And Lagowski, J. J. (2011). "The Systemic Approach to Teaching and Learning [SATL]: A 10-year Review." AJCE $1(1)$

[2] Alexander, C. (1964). Notes on the Synthesis of Form. Harvard University Press.

[3] Santos-Reyes, Jaime and Beard, Managing safety. "Journal of Loss Prevention in the Process Industries 21.

[4] Federal Emergency Management Agency (FEMA) (2007). Principles of emergency management supplement. Washington, DC: US

[5] Pine, J. C. (2009). Natural Hazards Analysis: Reducing the Impact of Disasters. CRC Press: Taylor \& Francis Group, FL: Boca Raton

[6] De Guzman, E. M. (2003). "Towards total disaster risk management approach." UN Publications website, Asian Conference on Disaster Reduction 2003 Kobe, Janpan.

[7] The Ontario Public Health Convention (TOPHC) (2014). "Rethinking the All-Hazards Approach-Moving from Response to Preparedness."

[8] The Ontario Public Health Convention (TOPHC) (2014). "Rethinking the All-Hazards Approach - Moving from Response to Preparedness." 